\title{
Pitfall in Ultrasound Evaluation of Uterine Scar from Prior Preterm Cesarean Section
}

\author{
Sarah-Maude B. Laflamme, M.D.,' 1 Nicole Jastrow, M.D., ${ }^{2}$ Mario Girard, R.T., 1 \\ Gaétan Paris, M.D.,' Laurie Bérubé, M.D., ${ }^{1}$ and Emmanuel Bujold, M.D., M.Sc. ${ }^{1}$
}

We report two cases of women with a previous cesarean performed before active labor at 29 weeks of gestation who underwent sonographic measurement of the lower uterine segment (LUS) at 36 weeks' gestation in their subsequent pregnancy. In both cases, uterine scar defect was detected on the upper part of the LUS, at $\sim 9$ to $11 \mathrm{~cm}$ from the cervical os, and was only visualized by the transabdominal approach. We suggest that early gestational age and the absence of labor at previous cesarean can lead to a higher uterine scar location on the LUS and, therefore, increase the risk of uterine rupture in subsequent pregnancy. The heterogeneity of uterine scar location could explain discrepancies observed in studies using the transabdominal versus the transvaginal approach or both regarding the predictive value of LUS measurements for uterine rupture.

KEYWORDS: VBAC, uterine rupture, lower uterine segment, ultrasound, dehiscence, scar, uterus

Measurement of lower uterine segment (LUS) thickness in women with previous cesarean has recently been proposed as a way of predicting uterine scar defects and uterine rupture. ${ }^{1,2}$ However, heterogeneity in the techniques employed, including the ultrasound approach (abdominal versus vaginal), has been associated with different results and cutoffs. ${ }^{1}$ Although transvaginal ultrasound is probably more reproducible, we report two cases in which abdominal ultrasound provided more accurate measurements. ${ }^{3}$

\section{CASE REPORTS}

\section{Case 1}

A 33-year-old woman (gravida 3, para 1) had a history of single, previous, low-transverse cesarean performed before labor at $29^{2} / 7$ weeks of gestation for breech, severe preeclampsia, and intrauterine growth restriction. The procedure was uneventful, and the hysterotomy was closed with a continuous, locking, single-layer suture. She underwent sonographic measurement of the LUS at 36 weeks' gestation in her next pregnancy 4 years later. Originally, the LUS was found to be $2.9 \mathrm{~mm}$ on transvaginal ultrasound (Fig. 1A). However, the transabdominal approach revealed a uterine scar defect (full LUS thickness of $1.4 \mathrm{~mm}) \sim 9 \mathrm{~cm}$ from the cervical os (Fig. 1B). She underwent elective repeat cesarean surgery at 38 weeks, during which complete uterine scar dehiscence was diagnosed.

\section{Case 2}

A 27-year-old woman (gravida 3, para 1) had her previous low-transverse cesarean at $29^{1} / 7$ weeks' gestation. At that

\footnotetext{
${ }^{1}$ Department of Obstetrics and Gynaecology, Faculty of Medicine, Université Laval, Québec, Canada; ${ }^{2}$ Geneva's University Hospitals, Geneva, Switzerland.

Address for correspondence and reprint requests: Emmanuel Bujold, M.D., M.Sc., Associate Professor, Department of Obstetrics and Gynaecology, Jeanne and Jean-Louis Lévesque Perinatal Research Chair, Faculty of Medicine, Université Laval, 2705 boulevard Laurier, Québec, QC G1V 4G2, Canada (e-mail: emmanuel.bujold@crchul.
}

\section{ulaval.ca)}

Am J Perinatol Rep 2011;1:65-68. Copyright (C) 2011 by Thieme Medical Publishers, Inc., 333 Seventh Avenue, New York, NY 10001, USA. Tel: +1(212) 584-4662.

Received: April 17, 2011. Accepted after revision: May 19, 2011. Published online: July 22, 2011.

DOI: http://dx.doi.org/10.1055/s-0031-1284222.

ISSN 2157-6998. 
A
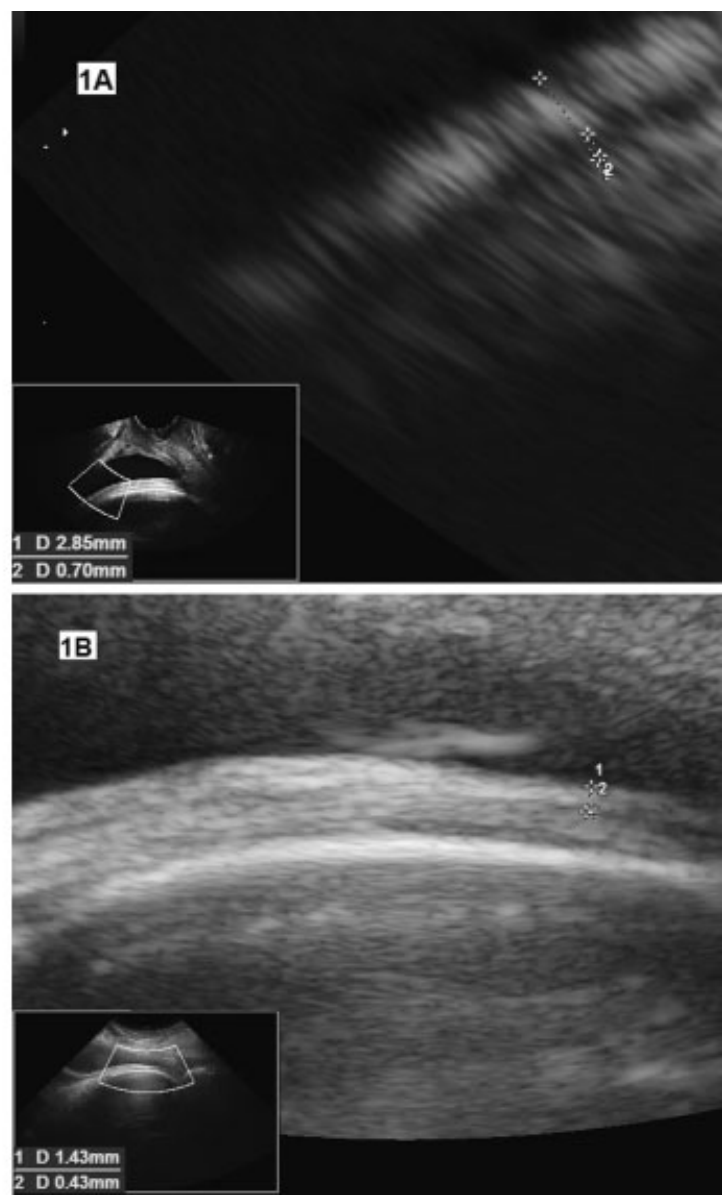

Figure 1 Measurement of lower uterine segment (LUS) thickness by transvaginal (A) and transabdominal (B) ultrasound performed at 36 weeks (case 1). In this case, transvaginal ultrasound revealed LUS thickness of $2.9 \mathrm{~mm}$, and transabdominal ultrasound demonstrated a thinner LUS portion located higher on the uterus.

time, she underwent labor induction with a Foley catheter and oxytocin because of severe preeclampsia and intrauterine growth restriction. Twelve hours after oxytocin initiation, no significant change in cervical dilatation was noted, and a cesarean was performed for a failed labor induction. The procedure was uneventful, and the hysterotomy was closed with a locking, continuous suture and an imbricating, continuous suture. Her LUS was measured at 36 weeks' gestation in her next pregnancy 3 years later. Transvaginal ultrasound did not reveal any evidence of uterine scar defect, and the LUS measured $2.7 \mathrm{~mm}$ (Fig. 2A). However, the transabdominal approach showed a LUS thickness less than $2.0 \mathrm{~mm}, \sim 11 \mathrm{~cm}$ from the cervical os (Fig. 2B). Elective repeat cesarean was undertaken at 39 weeks' gestation before labor. During surgery, a very thin LUS was observed, with vernix caseosa and the fetal part visible through complete uterine scar dehiscence (Fig. 3).
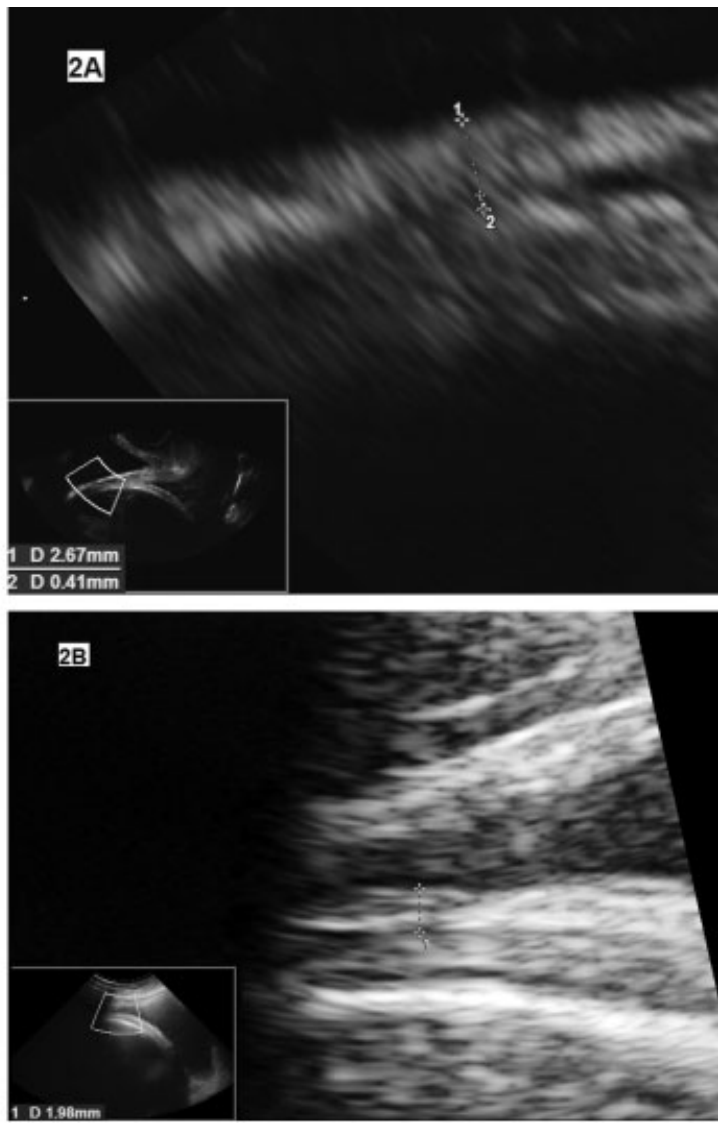

Figure 2 Measurement of lower uterine segment (LUS) thickness by transvaginal (A) and transabdominal (B) ultrasound performed at 36 weeks (case 2). Again, transabdominal ultrasound revealed a thinner LUS thickness, located higher on the uterus, than transvaginal ultrasound.

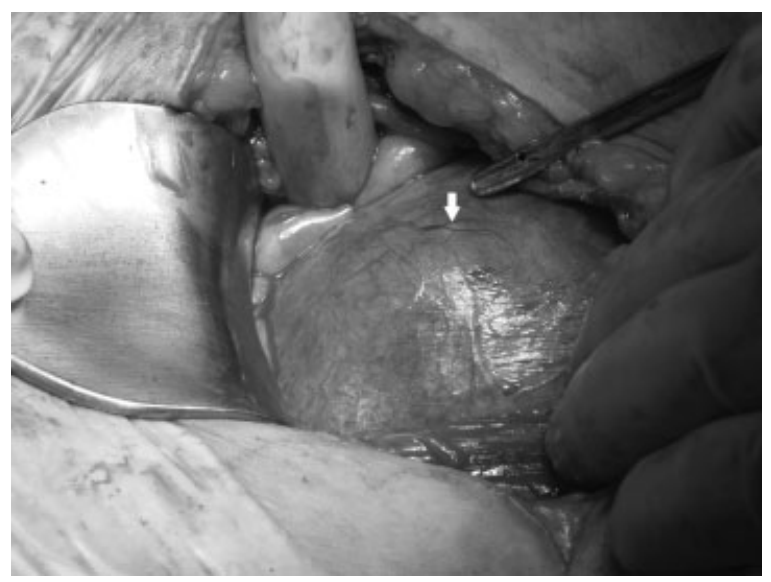

Figure 3 Uterine scar dehiscence during repeat cesarean. Lower uterine segment after opening of the parietal peritoneum (case 1). Particles of fetal vernix (white arrow) and fetal parts can be visualized through complete uterine scar dehiscence. 


\section{DISCUSSION}

These two cases indicate that transvaginal sonographic evaluation of LUS can miss significant uterine scar defects and that transabdominal measurement may be helpful when the scar is located on the upper part of the LUS. We hypothesize that gestational age at previous cesarean can influence uterine scar location on the LUS. In both our cases, early gestational age and the fact that cesareans were performed before or in early labor could have prompted higher incision on the LUS. Our finding is important because it could influence evaluation of uterine rupture risk and thus the choice of women contemplating a trial of labor after a previous cesarean.

In agreement with our observations, Sciscione et al reported that women with preterm cesarean are at increased risk of uterine rupture in a subsequent pregnancy compared with women who had a previous term cesarean. ${ }^{4}$ These authors suggested that the higher uterine rupture rate in this population could be related to (1) a greater likelihood of hysterotomy extension into the contractile portion of the uterus than in women with term cesarean, and/or (2) poor wound healing secondary to intrauterine infection and inflammatory cytokines associated with preterm births.

Labor before previous cesarean could also influence scar location on the LUS, corroborating the findings of Jastrow et $\mathrm{al}^{5}{ }^{5}$ who demonstrated that labor is linked with a thicker sonographic LUS in subsequent pregnancy than cesarean undertaken before labor. Similarly, Algert et al postulated that a history of labor before a primary cesarean could evoke a uterine scar defect on the lower part of the LUS and thus decrease uterine rupture risk in a subsequent trial of labor. ${ }^{6}$ The mechanism by which labor protects against uterine rupture could be the same, as suggested for preterm cesarean deliveries: labor might result in a better-developed LUS in that hysterotomy is less likely to involve contractile muscle and could lead to a lower uterine scar location. Although we believe that gestational age and labor can modify uterine scar location, we do not know to what extent they influence LUS thickness. Other factors could impact LUS thickness. ${ }^{5}$ In case 1 , prior, locking, single-layer uterine closure could be a risk factor for uterine rupture. ${ }^{7,8}$

We believe that the heterogeneity of uterine scar location could explain some of the discrepancies between studies taking only the transabdominal or transvaginal approach or both, regarding the predictive value of LUS measurement. ${ }^{2,9}$ Because sonographic LUS measurement is increasingly recognized as a useful clinical tool in the prediction of uterine rupture, it is important to be aware of the limitations of both these approaches. They should be performed routinely, especially in women with previous preterm cesarean and/or in women who had a previous cesar- ean before labor. We are convinced that the combination of parameters predicting a successful trial of labor and those foretelling uterine rupture, such as LUS thickness, could both ensure safer births in women contemplating a trial of labor after a previous cesarean. ${ }^{1,10-12}$

NOTE

Dr. Emmanuel Bujold holds a Clinician Scientist Award from the Canadian Institutes of Health Research.

\section{FUNDING}

This study was funded by the Jeanne and Jean-Louis Lévesque Perinatal Research Chair at Université Laval and by the Canadian Institutes of Health Research.

\section{REFERENCES}

1. Bujold E, Jastrow N, Simoneau J, Brunet S, Gauthier RJ. Prediction of complete uterine rupture by sonographic evaluation of the lower uterine segment. Am J Obstet Gynecol 2009;201:320; e1-e6

2. Jastrow N, Chaillet N, Roberge S, Morency AM, Lacasse Y, Bujold E. Sonographic lower uterine segment thickness and risk of uterine scar defect: a systematic review. J Obstet Gynaecol Can 2010;32:321-327

3. Marasinghe JP, Senanayake H, Randeniya C, Seneviratne HR, Arambepola C, Devlieger R. Comparison of transabdominal versus transvaginal ultrasound to measure thickness of the lower uterine segment at term. Int J Gynaecol Obstet 2009;107:140-142

4. Sciscione AC, Landon MB, Leveno KJ, et al; National Institute of Child Health and Human Development (NICHD) Maternal-Fetal Medicine Units Network (MFMU). Previous preterm cesarean delivery and risk of subsequent uterine rupture. Obstet Gynecol 2008;111:648-653

5. Jastrow N, Gauthier RJ, Gagnon G, Leroux N, Beaudoin F, Bujold E. Impact of labor at prior cesarean on lower uterine segment thickness in subsequent pregnancy. Am J Obstet Gynecol 2010;202:563; e1-e7

6. Algert CS, Morris JM, Simpson JM, Ford JB, Roberts CL. Labor before a primary cesarean delivery: reduced risk of uterine rupture in a subsequent trial of labor for vaginal birth after cesarean. Obstet Gynecol 2008;112:10611066

7. Bujold E, Bujold C, Hamilton EF, Harel F, Gauthier RJ. The impact of a single-layer or double-layer closure on uterine rupture. Am J Obstet Gynecol 2002;186:13261330

8. Bujold E, Goyet M, Marcoux S, et al. The role of uterine closure in the risk of uterine rupture. Obstet Gynecol 2010;116:43-50

9. Boutin A, Bérubé L, Girard M, Bujold E. Labour before a Caesarean section and the morphology of the lower uterine segment in the next pregnancy. J Obstet Gynaecol Can 2011;33:105 
10. Blackwell SC. Predicting VBAC success: from theory to clinical practice. Am J Perinatol 2009;26:691-692

11. Grobman WA, Lai Y, Landon MB, et al. Does information available at admission for delivery improve prediction of vaginal birth after cesarean? Am J Perinatol 2009; 26: 693-701
12. Grobman WA, Lai Y, Landon MB, et al; Eunice Kennedy Shriver National Institute of Child Health and Human Development Maternal-Fetal Medicine Units Network. Can a prediction model for vaginal birth after cesarean also predict the probability of morbidity related to a trial of labor? Am J Obstet Gynecol 2009;200:56; e1-e6 